\title{
Romances y pragmáticas de la historia
}

\section{Romances and practices in history Romances e pragmáticas da história}

Adán Salinas Araya ${ }^{1}$

Recibido: 06/08/2014 - Aceptado: 10/09/2014

\begin{abstract}
Resumen
El artículo trata sobre las visiones de la historia comprometidas en la gubernamentalidad neoliberal, pragmática y presentista, y sus relaciones con el fascismo utópico, futurista y destinal. Para iniciar este debate usa como punto de arranque los análisis y discusiones biopolíticas; al mismo tiempo se pregunta sobre las condiciones de una visión histórica de la filosofía que pueda servir de alternativa a las filosofías del origen o del destino sin diluirse en el debate sobre las épocas históricas.
\end{abstract}

Palabras clave: filosofía de la historia, neoliberalismo, fascismo, biopolítica.

\begin{abstract}
The article discusses the views of history involved in neoliberal governmentality - pragmatic and presentist - and its relations with the utopian, futuristic and destinal fascism. To start this discussion, it uses as starting point the analysis and bio-political discussionswhile it questions the conditions of a historical view of the philosophy that demonstrates an alternative to the philosophies of origin or destination without diluting in the debate about historical periods.
\end{abstract}

Key words: history philosophy - neoliberalism- fascism- biopolitics.

\section{Resumo}

O artigo trata-se de visões da história comprometidas na governamentalidade neoliberal, pragmática e presentista, e suas relações com o fascismo

1 Profesor de Filosofía y Licenciado en educación por la Universidad Católica Silva Henríquez, Magíster en Filosofía por la Universidad de Chile; Master en Estudios Avanzados de Filosofía y Doctor en Filosofía por la Universidad Complutense de Madrid. Actualmente es investigador de CENALTES y colaborador del departamento de Historia de la Filosofía en la Universidad Complutense de Madrid. Contacto: adan. salinas@cenaltes.cl 
utópico, futurista e destinal. Para iniciar este debate utiliza como ponto de partida a análise e discussões biopolíticas; ao mesmo tempo se questiona sobre as condições de uma visão histórica da filosofia que possa servir como alternativa para as filosofias da origem ou destino sem se diluir no debate sobre as épocas históricas.

Palavras-chave: Filosofia da História - Neoliberalismo - Fascismo - Biopolítica.

\section{Introducción}

El concepto imperio no se presenta como un régimen histórico que se origina mediante la conquista, sino que antes bien como un orden que efectivamente suspende la historia, en consecuencia, fija el estado existente de cosas para toda la eternidad ${ }^{2}$.

Entre los debates que se han llevado a cabo sobre la noción de biopoder y su aplicabilidad al presente, aparece según mi opinión un nudo problemático interesante a propósito de las posibilidades y las aporías de una noción de historia. Por una parte, la necesidad de considerar las singularidades históricas, particularmente si se quiere realizar un discurso sobre el presente y captar lo que le es propio. Por otra parte, la dificultad de establecer cortes históricos y visiones unitarias de una época, por ejemplo, como la modernidad, entendiendo que el dinamismo de las formaciones históricas es mucho más intrincado que los cortes que podamos hacer de la historia y de las 'representaciones epocales', como si en efecto se pudiese hablar de épocas históricas o caracterizar una época en forma unitaria. En tercer lugar, la relación con el pasado, con sus construcciones hegemónicas, historias oficiales y memorias subalternas, particularmente en cuanto el pasado 'dice algo' sobre el presente que vivimos. A continuación intento algunos acercamientos a estos problemas que atraviesan los discursos sobre el biopoder. No se trata ni de una descripción exhaustiva, ni menos aún de una 'solución' a este nudo, sino que busco evidenciar la presencia

2 HARDt, Michael; NeGRI, Antonio. Imperio. Trad. Alcira Bixio. Paidós, Barcelona, 2002, p. 16. 
de estos debates y también sugerir ciertos problemas epistemológicos y políticos que quedan en ellos implicados, y que en cierto sentido son síntoma de estas aporías en gran parte de la filosofía del siglo pasado.

\section{Fascismo utópico y eterno presente}

Esta 'suspensión de la historia', que denuncian Hardt y Negri, coincide con diversidad de análisis sobre el capitalismo actual respecto a su forma de auto-presentarse históricamente. Es decir, la pretensión de que el estado actual de cosas anularía cualquier posible evolución histórica y marcaría con ello una suerte de 'final de la historia'. Más allá del conocido -y actualmente renovado- Fukuyama, se trata de una de las visiones o representaciones históricas de carácter inmovilista altamente extendida. Ahora bien, lo verdaderamente decidor es que esta consideración del estado de cosas como un presente sin fin, o como fin(al) de la historia, constituye una representación de la historia distinta, pero relacionada con la idea de comunidad fundada en un origen o en un destino común, que en palabras de Esposito corresponde a la representación de la derecha romántica ${ }^{3}$.

Esta otra representación, en cambio, corresponde a la imagen del presente inmediato como único criterio histórico, más vinculado a lo que podría considerarse una derecha pragmática, pero no por ello carente de una representación histórica. Por el contrario, con una serie de representaciones de la historia muy particulares. Foucault también ayuda a comprender este asunto, particularmente en El nacimiento de

\footnotetext{
3 "¿Es «comunidad» una palabra que se pueda reconducir a «democracia»? ¿Puede, al menos, llegar a serlo? ¿O está demasiado arraigada en el léxico conceptual de la derecha romántica, autoritaria y racista? ...Se trata de una pregunta no sólo legítima, sino en ocasiones inevitable, en una fase en la que la cultura democrática se interroga sobre su propio estatuto teórico y futuro. Esto no quita para que sea, no obstante, una pregunta errada en su propia formulación o, en todo caso, mal planteada. Errada o mal planteada precisamente porque asume como indicador y término de comparación, para la ubicación de la categoría de comunidad, un concepto -el de la democracia-completamente incapaz de «comprenderla»". ESPOSITO, Roberto. Comunidad, inmunidad y biopolítica, Herder, Barcelona, 2010, p. 79.
} 
la biopolítica. De hecho, se puede asumir que uno de los efectos de la genealogía del neoliberalismo que realiza es precisamente mostrar el carácter histórico de la dinámica neoliberal, desmontar sus pretensiones naturalizadoras del presente. La genealogía del neoliberalismo propuesta por Foucault, sirve como punto de contradicción a la pretensión de esta deshistorización en la que el neoliberalismo se presenta como sistema total, último y definitivo.

Volviendo a la perspectiva de Hardt y Negri, es interesante recalcar que, respecto a esta representación de la historia y de los compromisos que afecta, los autores de Imperio, insisten en que no hay que volver sobre el romanticismo de las nacionalidades y los proyectos nacionales. Cualquier proyecto crítico al Imperio, o de resistencia, no puede ser regresivo. En primer lugar, porque sería un contrasentido cualquier añoranza de las anteriores formas de dominación; en cualquier caso, las disciplinas, la policía, la normalización, no son mejores que el Imperio. Además hay que entender que esta nueva situación es también un diagrama de articulación del poder y es necesario captar sus relaciones y palancas de fuerza. De hecho para Hardt y Negri, en esta nueva configuración global del poder hay mejores oportunidades de resistencia y transformación que en la antigua soberanía nacional.

"El imperio que se nos presenta hoy produce enormes poderes de opresión y destrucción, pero esta realidad de ningún modo debería hacernos sentir nostalgia por las antiguas formas de dominación. El paso al imperio y sus procesos de globalización ofrece nuevas posibilidades a las fuerzas de liberación ${ }^{\prime 4}$.

Desconocer las nuevas posibilidades, sería ceder a la estrategia de deshistorización, o de presente indefinido con que la lógica imperial se auto representa. Un nuevo orden sin tensiones, o con un poder muy por sobre los conflictos que se presentan, es decir, un orden indefinido y al mismo tiempo ultrapoderoso e infranqueable. En este sentido,

4 HARDT, Michael; NEGRI, Antonio. Imperio, 16. 


\section{no hay que olvidar que, pese a que la figura de Imperio $^{5}$ habla por sí}

5 El concepto de Imperio no deja de ser frágil, en todo caso en su valor descriptivo. Por una parte porque depende en su significación de las múltiples conexiones con las formas de poder de los imperios antiguos. Hardt y Negri en más de una ocasión proponen cierta alegoría de las condiciones de la Roma Imperial. Por otra parte, el soporte teórico de Hardt y Negri es en buena medida la tradición marxista, con lo cual la figura del Imperio debe medirse con los diagnósticos marxistas sobre el imperialismo, que desde Lenin o Rosa Luxemburgo han asumido este concepto para describir ciertas transformaciones del capitalismo. Precisamente este punto le ha valido a los autores de Imperio, algunas de las críticas desde los sectores más cercanos al análisis de Lenin. Me parece que esta es la clave por ejemplo del libro que Atilio Borón dedicó en forma de crítica a Imperio, es decir, que Hardt y Negri declaran superada la fase imperialista del capital y proponen comprender el nuevo régimen de acumulación, producción y regulación, como una fase imperial, sujeta a otras condiciones. Borón sostiene, en cambio, la vigencia del análisis de Lenin. "H\&N parecen no haberse percatado de que los actores estratégicos son los mismos, las grandes empresas transnacionales pero de base nacional y los gobiernos de los países industrializados; que las instituciones decisivas siguen siendo aquellas que signaron ominosamente la fase imperialista que ellos ya dan por terminada, como el FMI, el Banco Mundial, la OMC y otras por el estilo; y que las reglas del juego del sistema internacional siguen siendo las que dictan principalmente los Estados Unidos y el neoliberalismo global, y que fueran impuestas coercitivamente durante el apogeo de la contrarrevolución neoliberal de los años ochenta y comienzos de los noventa. Por su diseño, propósito y funciones estas reglas del juego no hacen otra cosa que reproducir incesantemente y perpetuar la vieja estructura imperialista bajo un ropaje renovado. Estaríamos mucho más cerca de la verdad si parafraseando a Lenin dijéramos que el imperio es la "etapa superior" del imperialismo y nada más. Su lógica de funcionamiento es la misma, como iguales son la ideología que justifica su existencia, los actores que la dinamizan y los injustos resultados que revelan la pertinaz persistencia de las relaciones de opresión y explotación". BORÓN, Atilio. Imperio e Imperialismo: Una lectura Crítica de Michael Hardt y Antonio Negri. CLACSO, Buenos Aires, 2002, p. 139. Además de estos argumentos, Borón encuentra puntos de apoyo indiscutibles en las políticas de recomposición del proyecto imperialista norteamericano de la administración Bush, expresado en las políticas orientadas desde el Project for a New American Century (http://www.pnac.info), uno de los núcleos ideológicos neoconservadores del partido republicano que tuvo una especial influencia en el gobierno de George W. Bush. Hardt y Negri han atendido parcialmente a estas críticas especialmente en Common Wealth, donde el paso del tiempo les ha permitido relativizar la influencia de este grupo neoimperialista, como un elemento existente pero no absoluto. Aunque la crítica de Borón tiene sentido desde cierta perspectiva, hay que lamentar que los ejemplos que entrega no son efectivos e incluso contradictorios. Porque este tipo de instituciones: OMC, Banco Mundial, FMl y otros organismos internacionales están fuera -evidentemente- del análisis de Lenin. Por el contrario, el monopolismo financiero e industrial es un proceso denunciado por Lenin que se ha seguido acrecentando y que tiene un volumen enorme en nuestros días. No sólo el proceso continúa, sino que incluso muchas de las compañías e instituciones mencionadas por Lenin se mantienen 
misma de un poder global y de un orden extendido y vasto, Hardt y Negri siempre están pensando en la multitud, como contrafuerza del diagrama, y en las posibilidades de reanudar un proyecto liberador o emancipador. Esta idea de las auto-representaciones de la lógica imperial es clave; de lo contrario, y si se pierde de vista el diagnóstico, rápidamente se comienza a hablar de un poder tan vasto y extendido, que no hay alternativa posible. Me parece que este tipo de discurso no es el de Hardt y Negri, es decir, el destino del análisis nunca ha sido llegar a afirmar: 'he aquí un poder tan grande que no hay lucha posible, he aquí un nuevo soberano que ha llegado para quedarse y que sólo describimos'. Me parece que ya en Imperio la dimensión conflictiva del planteamiento estaba presente y que se ha acrecentado aún más en Multitud. Independientemente de que la idea misma de Multitud sea

en la actualidad. Éste es un rasgo claro de continuidad. Me parece que el deslizamiento de casos que realiza Borón depende más de un diagnóstico táctico-político. Pues en Latinoamérica hemos experimentado muy directamente la intervención económica y especialmente política de los Estados Unidos durante todo el siglo XX y con especial énfasis a partir de la Guerra fría. De modo que las corrientes críticas han hablado de Imperialismo por varias décadas, proceso imperialista llevado a cabo por intervenciones directas, y apoyado por organizaciones internacionales como las que Borón y Negri mencionan en sentidos distintos. Pero este es un diagnóstico de las corrientes críticas latinoamericanas que utilizan el concepto propuesto por Lenin, y no un diagnóstico del propio Lenin. De modo que, en la argumentación de Borón se enlazan dos momentos, que pueden estar entrelazados, pero en ningún caso responden a un solo gesto teórico, sino a dos. De este modo, Borón enumera como un continuo las trasnacionales con base nacional y gobiernos de países industrializados -dos de los elementos basales en el planteamiento de Lenin-y luego el despliegue neoliberal, su instalación coercitiva y los organismos internacionales, elementos que no son señalados por Lenin en su diagnóstico del Imperialismo, sino que son asumidos por las corrientes latinoamericanas como síntoma de continuidad del imperialismo. Pero precisamente Negri está en desacuerdo con esto último. En realidad no hay motivo para señalar que Negri se opone al diagnóstico de Lenin; la postura de Negri es que estas lógicas de los organismos internacionales ya no son imperialistas, sino imperiales. Para decirlo claramente, se opone a la interpretación leninista latinoamericana. La crítica de Borón, entonces, es justificada vigente y cierta: hay muchos elementos del diagnóstico de Lenin presentes en la situación actual y que no se pueden obviar. Pero, tan justificada, como teóricamente confusa, pues termina homologando el análisis de Lenin con la lectura e interpretación leninista latinoamericana, que es sin duda una lectura posible e históricamente sostenida por décadas, pero una lectura. En resumen, la crítica es válida, pero hay que recomponerla con más delicadeza teórica. 
discutible ${ }^{6}$, la intención inicial es no ceder a la tentación de describir una forma de poder, sin describir, o proponer, sus contrafuerzas. O dicho de otro modo, no es posible aceptar la premisa inmovilista en la instalación de las nuevas articulaciones del poder y en su descripción. Si asumimos la noción Imperio como una descripción tentativa de una nueva forma de poder, entonces la idea Multitud deviene como su complemento lógico, en la medida que es necesario postular las contrafuerzas del diagrama. A pesar de las discusiones posibles que admite la idea de Multitud y por supuesto la idea de Imperio, lo que resulta muy claro es la implicancia de la una, al postular la otra. Me parece que es necesario quedarse con esta implicancia, aun cuando se discutan las categorías Imperio y multitud. La implicancia es precisamente ésta: una descripción del poder, especialmente tan vasta y extendida, exige explicitar también sus contrafuerzas. Es una exigencia estratégica, precisamente para no entregar un imagen abismante $u$ omnipotente de las estructuras políticas que se describen.

Quisiera retomar el problema de la auto-representación de la derecha romántica, que Esposito ha denunciado a propósito de la idea de co-

6 Hardt y Negri oponen el concepto de multitud al de pueblo. La propuesta se basa en que el concepto de pueblo denotaría un recurso identitario al que quieren renunciar en favor de un sujeto colectivo que se forma desde las múltiples singularidades y no desde la identidad. "El pueblo es uno. La población, obviamente, se compone de numerosos individuos y clases diferentes, pero el pueblo sintetiza o reduce estas diferencias sociales en una identidad. La multitud, por el contrario, no está unificada, sigue siendo plural y múltiple. Por eso la tradición dominante de la filosofía política postula que el pueblo puede erigirse en poder soberano y la multitud no". HARDT, Michael; NEGRI Antonio. Multitud. Guerra y democracia en la era del imperio. Debate, Barcelona, 2004, p. 127. En cualquier caso es necesario decir que aunque la intención teórica es rescatable, no hay que olvidar que los conceptos políticos están siempre en disputa y en tal sentido no veo la necesidad de ceder la categoría de pueblo a sus derivas identitarias como las que se relacionan con la experiencia fascista. En realidad me parece que tampoco hay que ceder conceptos como democracia, justicia o incluso el concepto de libertad, tan manoseado en la historia política del siglo XX como plataforma de legitimación ideológica del modelo económico. Incluso en este caso en que el concepto resulta tan envilecido, me parece que no hay que desconocer al mismo tiempo que esta instrumentalización, que estos mismos conceptos pueden ser-y han sido- palancas de procesos emancipatorios. En tal sentido creo que es importante elaborar nuevos conceptos, pero tampoco vale la pena mirar sólo la zona oscura de los conceptos políticos heredados de la tradición moderna. 
munidad. Me parece que se puede extraer una idea clave respecto a las filosofías de la historia que subyacen a este tipo de representaciones políticas. Pues mantienen una relación con un origen inalcanzable, pensado en términos de identidad común y unidad -tierra, raza, lengua, religión-; o también con un destino común o finalidad siempre inaprensible -pueblo elegido, comunidad de iguales, consumación de la historia, Reich-. Se trata de un desplazamiento hacia lo inalcanzable, muy propio del discurso fascista, en la medida que es un discurso utópico, que requiere la absolutización del sentido y la formación de un sentido capaz de movilizar a toda una comunidad, transformándola en comunidad de sentido. Quisiera traer a colación el análisis que Jean-Luc Nancy realiza sobre el papel del 'sentido', en la experiencia fascista:

"En este tiempo, el nuestro, están por un lado todos los riesgos de la espera de sentido, de la demanda de sentido (como esa banderola en Berlín, sobre un teatro, en 1933, 'Wir brauchen Leitbilder': 'tenemos necesidad de imágenes directrices') con todas las temibles trampas que semejante demanda puede tender"7.

La banderola aquella es síntoma de una representación de la historia y de la comunidad, que fue el motor de los proyectos políticos y el relato sobre la comunidad de una serie de proyectos que aquí menciono bajo el rótulo general de fascismo ${ }^{8}$; pero que pueden recibir múltiples nombres y que tienen en común la formación de un sentido, que puede servir como recurso de sentido absoluto para una comunidad. Origen y destino de la comunidad, equivalen a una

7 NANCY, Jean-Luc. El sentido del Mundo, La Marca, Buenos Aires, 2002, pp. 14-15.

8 Como plantea Negri, en la actualidad hablar de fascismo es casi sinónimo de hablar del mal a nivel político. Esta visión tiende a homogeneizar a veces procesos muy diferentes. Foucault, que tenía precisamente como antagonista al fascismo, tendía a estimar que se trataba de una suerte de constante política, incluso, podríamos decir, de algo que todos llevamos dentro. En particular cada vez más me inclino por reservar el rótulo de fascismo a los movimientos históricos precisos del siglo XX que se autonuclearon bajo este rótulo. Pero en cualquier caso queda por encontrar un nombre adecuado para aquella tendencia a la absolutez del sentido y negación de todo otro, que se manifiesta tanto al interior de cada uno de nosotros, como a través de formaciones políticas concretas. 
representación de la historia, que hoy es recurrida por una serie de admoniciones románticas en contra de la mundialización. En cierto sentido, de aquello es de lo que previene Hardt y Negri. Criticar y resistir esta lógica no puede significar retornar a los discursos locales de la identidad y a su configuración de sentido. Nancy también hace visible esta tendencia al parecer bienintencionada, intimista, comunitaria9. Es una de las tendencias de hecho que se afianzan en los nuevos fascismos europeos, desde Francia hasta Grecia. Probablemente el concepto de impolítico ${ }^{10}$ que Esposito presenta, sea el más lúcido en mostrar la posibilidad de una mirada histórica sobre los proyectos políticos que tome distancia de la teología política ${ }^{11}$ o de las políticas

9 "Los que ceden a la demanda de sentido... demandan al mundo que se signifique como residencia, abrigo, habitación, salvaguarda, intimidad, comunidad, subjetividad: significante de un significado propio y presente... Para ellos la mundialización del mundo, que es nuestro elemento y nuestro acontecimiento, el 'cosmopolitismo', la teletécnica, desapropian, des-significan el sentido, lo hacen jirones". NANCY, Jean-Luc. El sentido del Mundo, p. 15.

10 "¿Qué queda de estos fragmentos de pensamiento sobre la política-Pablo, Agustín, Maquiavelo, Pascal- en la Modernidad desarrollada, en el momento en el cual en torno al nombre de Hegel parece quedar atenazada la aparente alternativa de teología y nihilismo en una verdadera 'teología de la secularización'? He tratado de responder a tal pregunta relacionando la noción de 'impolítico' con una serie de autores muy diferentes entre ellos - de la última Arendt a Simone Weil, de Elias Canetti a Georges Bataille- si bien, una vez más, todos rigurosamente externos a la 'corporación' filosófico-política. Qué se debe entender con esta expresión -o tal vez sea mejor decir: qué invita a pensar- es lo que he intentado indicar, en los límites de un lenguaje inexorablemente inadecuado, en ese primer trabajo $y$, con una tonalidad más teorética, en estas mismas páginas. Digamos solamente que lo que une en una misma actitud 'impolítica' a tales autores es la búsqueda, no siempre consciente pero de cualquier modo altamente problemática y radical, de una 'tercera vía' que escapa a la repraesentatio teológico-política sin ceder, por otro lado, a la despolitización moderna". ESPOSITO, Roberto. Confines de lo político. Nueve pensamientos sobre política. Trotta, Madrid, 1996 p. 33.

11 Si bien la expresión 'teología política' puede tener un significado más amplio, me refiero aquí específicamente a lo que esto significa en la filosofía política del siglo XX, es decir a la legitimación del poder político absoluto a través de una concepción de la soberanía de matriz teológica. En cuanto a su implicación con el fascismo histórico el ejemplo más claro es el movimiento de la ReichsTheologie en la Alemania nazi: en cuanto al debate teórico esto se expresa especialmente en las discusiones sostenidas entre Schmitt y Peterson en los textos Teología Política I y Teología Política II de Schmitt y el Monoteísmo como problema político de Peterson. Para un tratamiento reciente de esta discusión -con el cual sin embargo tengo una serie de distancias- puede verse AGAMBEN, Giorgio. El Reino y la Gloria. Por una genealogía teológica de la economía y 
de la identidad, que me parece están en la base de la concepción de un 'sentido fuerte' como elemento configurador de la comunidad, ya sea explícitamente trascendente, o en las versiones secularizadas del sentido absoluto, como son las del origen y el destino. A propósito, traigo a colación un comentario de Nancy, precisamente sobre la relación entre el sentido como configurador de la comunidad y este tipo de representaciones, ya trascendentes, ya seculares.

"En realidad, es de la figura del "hombre" y, con ella, de la configuración del "humanismo", de la que nosotros sabemos apartarnos o desvincularnos, cuando tenemos las más potentes razones para no querer sustituirla ni por un 'superhombre' ni por 'Dios'". ${ }^{12}$

La proliferación del presente marca un cambio respecto al romance del fascismo utópico: la historia no se moviliza al origen porque es inaprensible; pero, por el contrario, siempre está en movimiento al destino, que es igual de inaprensible; en este caso, concebir la situación actual como presente ilimitado, como situación de llegada, que es lo que plantea la lógica imperial, inmoviliza la historia y anula la posibilidad de todo cambio social. Lo imperial es entonces punto de llegada, lógica omnipresente, omniabarcante, y a la vez proceso desbordante inmanejable y destino común.

Hay un juego interesante entre dos posibilidades de representación histórica, la representación romántica del origen y del destino, que implica una relación con el tiempo inaprensible, con un ori-

el gobierno. Homo sacer II, 2. Pre-textos, Valencia, 2008, pp. 25-35; 80-95; 147-159. También puede apreciarse esta discusión en HOLLERICH, Michael. Catholic AntiLiberalism in Weimar: Political Theology and its Critics En KAPLAN, Leonard; KOSHAR, Rudy. "The Weimar Moment: liberalism, political theology and law». Lexington, Maryland, 2012. Y en los estudios de la biógrafa de Peterson. Ver NICHTWEIß, Barbara. Analogías y oposiciones. Los Tratados teológicos de Erik Peterson en la perspectiva de la relación Iglesia-Estado. En «COMMUNIO». III Época, Año 25, Octubre-Diciembre, 2003. También, NICHTWEIß, Barbara. Erik Peterson. Neue Sicht auf Leben und Werk. Herder, Freiburg, 1994.

12 NANCY, Jean Luc. La creación del Mundo o la mundialización. Paidós, Barcelona, 2003, p. 22. 
gen o un destino que siempre están más allá. Y por otra parte, la representación del presente ilimitado, del momento actual como consumación pragmática. Ésta es, me parece, la representación prevalente, aunque las teogonías del origen y las escatologías del destino no han desaparecido. Se trata de una representación de la historia, que anula la historia; no porque sea la consumación de su progreso o subsuma como finalidad el desarrollo anterior. 'Fin de la historia' no quiere decir síntesis o culminación, sino proliferación del presente, oscurecimiento de los procesos históricos y negación de que el presente mismo tenga una historia, un curso y por lo tanto transformaciones y derivas. Representación de la derecha pragmática, completamente diferente al romanticismo fascista. Por supuesto que hay múltiples vínculos políticos concretos entre la pragmática neoliberal y el fascismo utópico; pero se relacionan desde visiones de la historia diferentes.

La vocación de cambio y transformación del fascismo destinal, es precisamente lo que sedujo por ejemplo al futurismo italiano; porque el destino empuja hacia el futuro, hay un futuro que construir (uno solo, de eso se trata todo), y esta necesidad urge, moviliza, tiene el carácter de un desafío y de una misión. La visión del origen sirve como punto de retorno, una vez construida la imagen hay que volver a ella, recobrar la memoria, suspender el olvido de los proyectos que erraron en el camino, superar el pecado original que consistió en alejarse del origen: volver a ser griego, volver a ser romano, volver a ser cristiano. No importa en definitiva cuál de las imágenes perdidas es la que alimenta esta vocación de retorno, lo importante es que la historia es un extravío, una pérdida, un olvido ${ }^{13}$. Por el contrario la

13 A propósito de las filosofías del olvido resultan interesantes los comentarios de Foucault respecto a su propio trabajo. La genealogía foucaulteana no puede ser considerada como punto de apoyo de estas filosofías del olvido. "(...) mi discurso, lejos de determinar el lugar de donde habla, esquiva el suelo en el que podría apoyarse. Es un discurso sobre unos discursos; pero no pretende encontrar en ellos una ley oculta, un origen recubierto que sólo habría que liberar; no pretende tampoco establecer por sí mismo y a partir de sí mismo la teoría general de la cual esos discursos serían los modelos concretos. Se trata de desplegar una dispersión que no se puede jamás reducir a un sistema único de diferencias, un desparramiento que no responde a. unos ejes absolutos de referencia; se 
lógica imperial -si queremos llamarle de este modo- se alimenta de otra representación de la historia: la proliferación del presente. Un presente invencible, inmodificable.

Tenemos aquí distintas representaciones de la historia, pero que albergan un sentido político curiosamente entrecruzado. Las representaciones de la derecha romántica, que busca el origen perdido, olvidado, se entienden bien con las ideas de una derecha destinal. Pero la proliferación de un presente eterno, habla de una representación histórica y de una derecha completamente diferente. El objetivo ya no es la utopía del destino común.

\section{La periodización histórica}

Se ha debatido bastante sobre el problema del "tiempo de la biopolítica", expresión que utiliza Esposito ${ }^{14}$. Al parecer el asunto está más o menos zanjado, Foucault situaría el problema del biopoder como un problema moderno y que llega hasta la actualidad. Esposito también, aunque en alguna ocasión utiliza el término postmodernidad y

trata de operar un descentramiento que no deja privilegio a ningún centro. Tal discurso no tiene como papel disipar el olvido, hallar, en lo más profundo de las cosas dichas y allí donde se callan, el momento de su nacimiento (ya se trate de su creación empírica, o del acto trascendental que les da origen); no pretende ser recolección de lo originario o recuerdo de la verdad. Tiene, por el contrario, que hacer las diferencias: constituirlas como objetos, analizarlas y definir su concepto. En lugar de recorrer el campo de los discursos para rehacer por su cuenta las totalizaciones suspendidas, en lugar de buscar en lo que ha sido dicho ese otro discurso oculto, pero que permanece el mismo (en lugar, por consiguiente, de desempeñar sin cesar la alegoría y la tautología), opera sin cesar las diferenciaciones, es diagnóstico. Si la filosofía es memoria o retorno del origen, lo que yo hago no puede ser considerado, en ningún caso, como filosofía; y si la historia del pensamiento consiste en dar nueva vida a unas figuras casi borradas, lo que yo hago no es tampoco historia". FOUCAULT, Michel. La arqueología del Saber. Siglo XXI, Buenos Aires, 1999, pp. 345-346.

14 "La conexión estructural entre modernidad e inmunización nos permite dar un paso adelante también en relación con el «tiempo» de la biopolítica. Hemos señalado que el propio Foucault oscila entre dos posibles periodizaciones $-y$, por consiguiente, interpretaciones- del paradigma que él mismo inauguró". ESPOSITO, Roberto. Bíos, Biopolítica y Filosofía. Amorrortu, Buenos Aires, 2006, p. 78. 
sugiere que la biopolítica sería también una cuestión postmoderna ${ }^{15}$. Hardt y Negri se inclinan a pensar que se trata de un asunto sobre todo postmoderno, aunque evidentemente es también moderno ${ }^{16}$. Y quizás el único que tiende a pensar el problema como una constate histórica, o dimensión de la política en todo tiempo, es Agamben, con lo cual evidentemente habría una biopolítica en la antigüedad ${ }^{17}$. Como decía, el panorama parece claro al respecto.

Este debate tiene dos problemas; por una parte se ha imbricado con la noción de postmodernidad que propiamente no es parte del léxico foucaulteano. Incluso los términos moderno y modernidad son poco frecuentes en Foucault, quien prefiere hablar de época clásica para el periodo del antiguo régimen. $Y$ evidentemente, al imbricarse con esta problemática de la postmodernidad, traslada a este terreno del biopoder las dificultades de la idea de postmodernidad. Me parece que estas dificultades se pueden resumir en algunos puntos: A) Suposición de una modernidad unitaria, aunque es una idea cada día menos aceptada; B) la dificultad práctica que muestra la vigencia de múltiples rasgos modernos en la vida actual, que lejos de estar debilitados parecen muy prósperos; C) dispersión léxica de la idea de postmodernidad y posmodernismo, de modo que tales conceptos tienen sentidos muy diferenciables en el arte, en la sociología y en la filosofía, lo que ha vuelto común que se hable de postmodernidad, o de postmodernismo en sentidos antagónicos y equívocos; D) que se tienda a consolidar como categoría de una forma de pensamiento, por ejemplo al hablar de 'filósofos postmodernos' e incluso 'postmodernistas', en forma análoga a como se habla por

15 Ver ESPOSITO, Roberto. Bíos, Biopolítica y Filosofía, p. 84 ss.

16 "En la posmodernización de la economía global, la creación de la riqueza tiende aún más hacia lo que llamaremos la producción biopolítica, la producción de la vida social misma, un proceso en el cual cada vez más lo económico, lo político y cultural se superponen e invierten recíprocamente". HARDT, Michael; NEGRI, Antonio. Imperio, p. 15.

17 "La presente investigación se refiere precisamente a ese punto oculto en que confluyen el modelo jurídico-institucional y el modelo biopolítico del poder. Uno de los posibles resultados que arroja es, precisamente, que esos dos análisis no pueden separarse y que las implicaciones de la nuda vida en la esfera política constituyen el núcleo originario-aunque oculto- del poder soberano". AGAMBEN, Giorgio. Homo Sacer. El poder Soberano y la Nuda Vida. Pre-Textos, Valencia, 1998, p. 15. 
ejemplo de 'artistas postmodernos y postmodernistas'; para decir, no obstante, algo completamente distinto. Si se comparan la primera y última de estas dificultades, resulta explícito el equívoco central del asunto, entre quienes hablan de postmodernidad para referirse a un periodo histórico (un momento, un estado de la cultura, etc.) y entre quienes hablan de postmodernidad para referirse a una corriente o un estilo de pensamiento y de desarrollo cultural afín (artes visuales, arquitectura, literatura, por supuesto filosofía). Las dificultades y equívocos de estas discusiones quedan entonces, por fuerza, instaladas en los discursos sobre el biopoder en la medida que tal categoría -postmodernidadaparece en tal o cual discurso.

Se trata de un asunto bastante complejo y si bien me atrevo aquí a resumir los problemas que me parecen más vistosos en torno a la cuestión de la postmodernidad, no es realmente lo que me interesa, sino el problema de la periodización, que no sólo toca ya la idea de postmodernidad; sino a la posibilidad misma de situar el desarrollo de ciertos diagramas de poder en coordenadas históricas. Es cierto que sobre todo Hardt y Negri, insisten en la expresión postmodernidad, pero la cuestión de fondo es cómo el problema del biopoder debe situarse históricamente o no. Nadie dirá que el problema del biopoder está exento de la situación histórica; pero en efecto hay en juego consideraciones históricas diversas.

Quiero abordar la cuestión por el tramo final del problema, trayendo a colación el último de los cursos que Derrida, dictó, titulado La Bestia y el Soberano. El curso, en algunos momentos, se plantea derechamente el problema del biopoder y además comenta extensamente el Homo Sacer de Agamben. Derrida, emprende una crítica al italiano, en muchas ocasiones desmesurada e incluso argumentalmente injusta. Pero le concede un punto de lo más problemático. Quisiera atender en detalle al argumento.

"...el propio Agamben, lo van a oír ustedes, tomando en serio la idea de Foucault de una biopolítica específicamente moderna, se empeña en recordar que ésta es lo más antigua posible, inmemorial y arcaica. (...) constituye un cuestionamiento particularmente abrupto de la tesis de Foucault 
sobre la modernidad de lo bio-político (...), a saber, que lo que parece moderno, lo van a oír ustedes, es en verdad inmemorial. Voy a leer pues, pero tras un largo rodeo, este parágrafo que, por otra parte, renuncia a cualquier determinación específicamente moderna de una bio-política del Estado que no haría, lo van a oír ustedes, sino reanudar con lo arcaico y lo más inmemorial" ${ }^{\prime \prime}$.

Quisiera detenerme aquí en dos cosas. La primera es sólo un recordatorio, que aprovecho de enfatizar con el apoyo de Derrida: Foucault había situado el problema biopolítico como un asunto moderno. En segundo lugar, según Derrida, la biopolítica desbordaría la modernidad; este desborde no sólo apunta hacia la "antigüedad", sino hacia lo arcaico e inmemorial. Aquí se genera un efecto del que hay que saber distinguir las consecuencias. Cuando Hardt y Negri insisten en que el problema biopolítico se relaciona con la postmodernidad, lo que están haciendo es conducir el discurso hacia el terreno que quieren, lo cual es lícito; y es exactamente lo que está haciendo Derrida al conectar esto con la idea de lo inmemorial. Derrida acuerda y profundiza la perspectiva de Agamben. Es un acuerdo que debe llamar la atención, pues en realidad, Derrida hace ver su desacuerdo en casi todo con el análisis de Agamben, lo que puede atestiguarse en decenas de páginas a lo largo del curso. Derrida evidentemente reconoce que hay elementos nuevos de carácter biopolítico ${ }^{19}$, lo hace en varias ocasiones, a lo largo del argumento; pero insiste, como lo ha mostrado la cita anterior, que fundamentalmente la biopolítica es algo antiguo. Es decir, concuerda con Agamben, y lo hace reconociendo abiertamente que esto no es lo que pensaba Foucault. En la base de tal afirmación hay una convicción de Derrida, que se distancia de una

18 DERRIDA, Jacques. La bestia y el soberano; Volumen I, 2001-2002. Manantial, Buenos Aires 2010, p. 370.

19 "Lo que más me sorprende, por lo demás, y nunca dejará de desconcertarme en la argumentación y en la retórica de Agamben es que reconoce claramente lo que acabo de decir, a saber, que la bio-política es algo archi-antiguo (aunque, hoy en día, tenga nuevos medios y nuevas estructuras)" DERRIDA, Jacques. La bestia y el soberano; Volumen I 2001-2002, p. 384. 
forma de pensar la historia ${ }^{20}$, distancia con una imagen lineal de la que depende la operación misma de "periodizar". Agamben y Foucault podrían discutir si la biopolítica pertenece a un periodo moderno, o no; pero según la perspectiva de Derrida, este mismo gesto los sitúa al interior de una misma concepción de la historia ${ }^{21}$. Esta concepción de la historia debe ser interrogada, pues ofrece una imagen dudosa. Conceptos antiguos, que siguen estando vigentes, por otra parte, una modernidad que se resiste a morir, a pesar de los múltiples anuncios de su desahucio.

\author{
"Que, aquí, no haya ni simple sucesión diacrónica ni simple \\ simultaneidad sincrónica (o que haya ambas a la vez), que \\ no haya ni continuidad del paso ni interrupción o simple \\ cesura, que los motivos del paso de lo que pasa y ocurre en
}

\begin{abstract}
20 "¿Por qué insistir tanto en el detalle de estos textos, por ejemplo aquí los de Agamben y de Foucault(...)?: pues bien, porque estos textos son muy interesantes -repito-y se dirigen a lo más vivo de lo que nos importa aquí pero, sobre todo, porque las dificultades con las que se encuentran, las confusiones y las contradicciones que acabamos de descubrir en ellos (por ejemplo, al pretender descubrir por primera vez unos acontecimientos absolutamente nuevos, "decisivos y fundadores» de los cuales se dice, al mismo tiempo, que no tienen edad y que, de hecho, son «inmemoriales», etc.), todo eso nos obliga -y hay que estarles agradecidos por ello- a reconsiderar, justamente, una forma de pensar la historia, de hacer historia, de articular una lógica y una retórica con un pensamiento de la historia o del acontecimiento.

Volver a poner en cuestión no sólo ese afán de periodización que adopta semejantes formas (una modernidad que no sabemos dónde comienza ni dónde acaba, una edad clásica cuyos efectos todavía son perceptibles, una antigüedad griega cuyos conceptos están más vivos y sobrevivientes que nunca, ese presunto «acontecimiento decisivo de la modernidad» 0 «acontecimiento fundador de la modernidad» que no hace sino poner de manifiesto lo inmemorial, etc.), no es reducir la acontecibilidad o la singularidad del acontecimiento". DERRIDA, Jacques. La bestia y el soberano; Volumen I, 2001-2002, p. 387.

21 "Tengo más bien la tentación de pensar que dicha singularidad del acontecimiento es tanto más irreductible y desconcertante, como debe serlo, cuanto que se renuncia a esa historia lineal que sigue siendo-a pesar de todas las protestas que, sin duda, ellos elevarían contra esta imagen- la tentación común de Foucault y de Agamben (la modernidad que viene después de la edad clásica, las épistêmê que se suceden y se tornan caducas unas a otras, Agamben que viene después de Aristóteles, etc.), que se renuncia a esa historia lineal, a la idea de acontecimiento decisivo y fundador (sobre todo si se intenta volver a pensar y a evaluar la experiencia paciente y aporética de lo que quiere decir «decisión» en la lógica de la excepción soberana), que se renuncia a la alternativa entre lo sincrónico y lo diacrónico, alternativa que no deja de presuponerse en los textos que acabamos de leer". DERRIDA, Jacques. La bestia y el soberano; Volumen I, 2001-2002, p. 387-388.
\end{abstract}


historia no dependan ni del fundamento sólido ni de la decisión fundadora, que el paso no tenga, bajo él, ningún suelo fundador ni ninguna línea indivisible, nos obliga a volver a pensar la figura misma del umbral (suelo, solidez fundadora, límite entre el adentro y el afuera, la inclusión y la exclusión, etc.). Lo que los textos que hemos leído reclaman es, al menos, una vigilancia más grande con respecto a nuestro irreprimible deseo del umbral, de un umbral que sea un umbral, un único y sólido umbral. Quizá nunca haya umbral, un umbral semejante. Quizá por eso nos quedamos en él y nos arriesgamos a permanecer para siempre en el umbral"22.

Me parece que se trata de un problema para tomarse en serio. Todo el problema de la periodización histórica, particularmente cuando se pretende tener umbrales muy determinados, o etapas unitarias, en realidad es mucho más un espejismo de ciertas tradiciones historiográficas que una constatación. Y la serie de preguntas que se realiza Derrida, son preguntas necesarias de atender: ¿Quizá las formas de periodización son sólo un deseo no resuelto que busca tener alguna solidez, cuando lo que en realidad existe es más bien vacío y abismo, que suelo sólido y permanente?, ¿quizá la figura misma de la línea y la concepción lineal del tiempo no son sino una trampa para simular que se pasa, que se cambia, que algo se sucede a otro algo, mientras las relaciones de continuidad y quiebre atienden a una dinámica mucho más compleja?, ¿quizá la oposición entre sincronía y diacronía tiene sentido sólo para la lógica de las oposiciones binarias, pero en realidad tal distinción sólo esconde una tensión y una simultaneidad históricas que no alcanzamos a ver, precisamente a causa de esta estructura binaria? Como digo, todas estas me parecen preguntas no sólo validas; sino que abren un problema latente en los discursos sobre el biopoder, más allá de categorías como moderno o postmoderno. Se trata de un problema incluso metodológico, en la medida del tratamiento que damos a las propuestas sobre el problema del biopoder. Pero también es cierto, y esto vale la pena tenerlo en cuenta, que a esta serie de preguntas que 
Derrida ofrece, es posible oponer otra serie de preguntas, también de la mayor importancia y que apuntan en la dirección contraria: ¿Cómo atender que en efecto existe transformación histórica, si negamos toda forma de periodización, o hay que asumir que la transformación es aparente y que los sucesos sólo repiten o remiten a acontecimientos más profundos y comunes a todo tiempo?, ¿no es cierto que sucesos históricos al mismo tiempo que se asemejan a otros sucesos de otro tiempo, o intemporales e inmemoriales, también encierran algo inédito e inaudito?, ¿en términos epistémicos, si la periodización tiene problemas, anularla los resuelve?, ¿en términos políticos, lo indiscernible del paso o del umbral, qué representación de la historia nos sugiere?

Como se ve, las dificultades del problema de la periodización que Derrida hace explícitas, en realidad arrojan una serie de nuevas dificultades. Se perfila una cierta aporía. Ante ella me parece que Negri es quien entrega el criterio más razonable al respecto.

"Cuando aparece una nueva configuración del tejido histórico, se advierte también un cambio importante en la perspectiva epistemológica. Los métodos del conocimiento y del enfoque real se modificarán, mucho más desde el punto de vista práctico, es decir, de la inserción de la episteme en lo real, lo cual significa desde el ángulo de los dispositivos de la acción" ${ }^{23}$.

Es decir, hay que admitir que aunque la periodización histórica tenga inconvenientes, esto no anula que de hecho se generen cambios históricos, y más allá de que se les designe e incorpore en un periodo u otro, es importante ver que estos cambios repercuten en dos niveles. Primero, en su relación con la episteme, con las modalidades específicas del saber, sus objetivos, los procedimientos de producción de esos saberes; y en segundo lugar, respecto a la relación de esa episteme con las configuraciones sociales específicas, y los dispositivos de acción. El criterio es tan razonable como práctico: Independientemente de las

23 NEGRI. Antonio. Guías. Cinco lecciones en torno a Imperio. Paidós, Barcelona, 2004, p. 73. 
aporías epistémicas que algo así como un concepto de historia arrastre, hay sucesos que es necesario describir, a los que es irrenunciable referirse. ¿Qué sucedería de lo contrario? Inmovilidad de la teoría social, parálisis del pensamiento, abandono de los sucesos históricos a las fuerzas contingentes y los poderes fácticos, consagración de las hegemonías. Hay que detenerse en esto un momento; pues mientras el fascismo utópico requería un concepto de historia que empujara al origen o al destino, la lógica imperial requiere una historia suspendida. Mientras el fascismo se definía por los sentidos con que signaba la historia; siempre sentidos fuertes, absolutos, colectivos, capaces de movilizar a grandes multitudes y hacerlas actuar como un sujeto unitario. Un sentido capaz de volverse eje unitario, del arte, de la ciencia y de la militancia; pero la lógica neoliberal requiere la atomización del sentido. Que lo que persigan los sujetos sea siempre un sentido individual, incluso nunca un sentido completo, sino parcial, proyectos parciales y provisorios, incomunicables. Por tales razones es importante resguardar que incluso las dificultades epistémicas de la periodización histórica no pueden ser una plataforma epistémica para la neutralización de todo juicio sobre la historia, y de toda descripción de los sucesos históricos.

Ante lo anterior siempre puede levantarse alguna voz que diga: 'Derrida le hace el juego a la lógica Imperial, criticar la periodización histórica es funcional al capitalismo avanzado'. Pero eso es leer a medias. El problema epistémico existe y es importante. Pero al mismo tiempo, es importante situar estratégicamente este problema, de manera que aquello que no tenemos claro, no se vuelva una plataforma de apoyo de una derecha presentista que elimina toda discusión histórica y mantiene un ideario de consumación pragmática del presente.

\section{Origen y retorno}

Pienso que la imagen nietzscheana del eterno retorno hace guiños, por una parte, desde una filosofía del acontecimiento; y por otra, desde una teoría de lo arcaico. Virno recuerda de manera verdaderamente práctica el valor de las propuestas de Benjamin a este respecto. 
"En el fondo, las tesis sobre la filosofía de la historia de Walter Benjamin me parece que van en este sentido, en esta dirección: que un momento presente se liga, dice Benjamin, en constelación con un momento muy lejano pero con el que hay una especie de semejanza preciosa. Bueno, esto es decisivo para no ser progresista" ${ }^{24}$.

Este planteamiento me parece útil para ilustrar cómo el proceder de Agamben funciona precisamente queriendo acceder a estas semejanzas preciosas. Lo digo también, porque he criticado fuertemente a Agamben por su efecto de deshistorización y sostengo esa crítica; pero entiendo profundamente las causas de este problema. Mi hipótesis en esto, es que la perspectiva histórica de Benjamin, particularmente en la relación entre el pasado y el presente, es una forma de leer el problema del eterno retorno, al igual que la idea de la repetición en Deleuze. Que es el fundamento, precisamente, de una filosofía del acontecimiento. No quisiera intentar solucionar un problema de esta envergadura; por lo tanto propongo lo siguiente como un juego de suposiciones, ante el cual quienquiera puede pronunciarse.

Supongamos que el eterno retorno no es una clave para una ontología de la historia, sino para una concepción trágica de la existencia. En nuestro caso, y con el lenguaje que aquí ocupamos, sería más bien una clave para la subjetividad, para una estilística de la existencia, no para una filosofía de la historia. Es cierto que según lo que aquí planteo, una estilística de la existencia es lo contrario a un universal antropológico, es una haecceidad, una existencia única y singular, que no requiere entonces de una ontología; por el contrario, se está mejor sin ella. Supongamos que esta estilística puede ir más allá de lo que propuso Foucault y ser un ejercicio de subjetividad colectiva. ¿No puede este proceso explicar también la elección de los predecesores históricos y de los futuros posibles? ¿No es también una forma de no ser progresista? Hay que recordar que Agamben, además de asumir las constelaciones de Benjamin, hace interactuar

24 VIRNO, Paolo. Gramática de la multitud. Para un análisis de las formas de vida contemporáneas. Traficantes de sueños, Madrid, 2003, p. 138. 
tales constelaciones con la idea de providencia. Pues es exactamente el caso que me interesa. La providencia es una metafísica del progreso, como los arcanos o los acontecimientos son una metafísica del eterno retorno. Pues sustraigámonos de esta operación. ¿No es posible pensar los futuros posibles y las precedencias históricas como una operación inmanente?

Pensemos en la idea de destrucción del presente en Benjamin: 'El presente debe ser destruido para forjar un futuro; puede hacerse esto desde el pasado, en la medida que se retoma el pasado de los vencidos'. Pero por supuesto que podemos elegir el futuro posible y el pasado a retomar. No se trata de que retorne inexorablemente un mismo acontecimiento. $\mathrm{O}$ de acceder a un plano de arcanos subsistentes e inevitables. Pensemos el asunto al revés, no nos fijemos en lo ontológicamente pensable o convincente, sino en lo que necesitamos tácticamente. Se trata de desactivar el fin de la historia, el eterno presente o la pragmática del instante, todos ellos relatos de la gubernamentalidad neoliberal globalizada o en vías de globalización. En términos prácticos: desactivar la idea de que con la globalización del neoliberalismo financiero no hay otra transformación posible, a no ser pequeñas evoluciones y adaptaciones internas del sistema. Esto requiere, entonces, activar una idea de la historia; pero una idea de la historia que no quede seducida por el progresismo, ni el utopismo del destino, o el romanticismo del origen. Pero además, con las salvaguardas epistémicas que implican intentar periodizar o ponerse ante los relatos unidimensionales de la modernidad. Se trata entonces de una idea de la historia que cumpla con las condiciones anteriores y que permita transformar el presente, construir el futuro, releer el pasado.

La desactivación de la historia es una condición del neoliberalismo global en su doble juego. Es decir, tanto en su pragmática del instante, como en la proliferación del presente en presente eterno. Pensemos un poco este doble juego. A partir de la crisis del 2008, se podría pensar que esta representación de final de la historia, o de permanente presente podría entrar en crisis. Pero en realidad se genera un efecto mucho más complejo. Me parece relativamente fácil admitir que, equivocado 
o acertado, lo que plantean Hardt y Negri está en proceso. La imagen que describen, aunque se muestre a sí misma como presente, en realidad está formándose, está por venir. Es decir, las condiciones que la hacen posible se están construyendo en este preciso momento. $Y$ al contrario de la imagen proyectada, se trata de un proceso que no se forma solo, que no aparece espontáneamente; sino que requiere grandes transformaciones y una intervención constante para que llegue a realizarse. Esto lo aprendimos con Foucault ${ }^{25}$.

El hecho de que este proceso se afirme en la imagen de su propia naturalidad, no quiere decir que en realidad sea un proceso natural. Su propia naturalización es una estrategia, se representa como espontáneo, permanente e inmodificable, se naturaliza: pero no es natural, es un artificio, una construcción. Y se trata de una construcción que aún requiere transformaciones importantes, especialmente en el mundo árabe y africano, pero también en Europa. Es interesante pero la crisis ha sido precisamente la oportunidad para que la derecha europea emprenda transformaciones radicales a la estructura social; ninguna de estas transformaciones se dirige a transformar los elementos estructurales del capitalismo financiero que produjo la crisis; por el contrario, estas transformaciones buscan profundizar y extender las estructuras del capitalismo financiero a toda la estructura social. $Y$ toda esta serie de restructuraciones se realizan precisamente bajo una pragmática del instante. El relato de la transformación europea no se pregunta por el porvenir, ni siquiera tiene un proyecto de futuro que mostrar. La idea permanente es salvar lo que hay, salvar el instante. Es una pragmática que desactiva la historia. No hay historia, sólo el instante actual, necesitado además de rescate. Esta es una parte del juego, que se complementa con la inmovilización de la historia, que es parte de la estrategia que denuncian Hardt y Negri; es una visión interesante, pero aún una visión del futuro. En este momento, no ve-

25 Este es probablemente uno de los aportes importantes de El nacimiento de la biopolítica: mostrar que nunca una economía de mercado, menos aún una sociedad totalmente administrada y atravesada por una racionalidad de mercado, llega a formarse de manera espontánea. Por eso el neoliberalismo tiene una relación clara y autoconfesada con el poder político, la propaganda y la formación de subjetividad. 
mos pax imperial ni quietud; por el contrario, vivimos un momento de enormes transformaciones estructurales, realizadas como pragmáticas del instante. Pero tiendo a pensar con Hardt y Negri que el efecto final es esa suerte de quietud, o inmovilidad de la historia que ellos llaman Imperio. Esta es la segunda parte del juego.

Hace unos 30 años se publicó un libro de título inquietante: La revolución silencios $a^{26}$. Se han escrito varias líneas para mostrar que eso no fue realmente una revolución, que una revolución no es sólo una transformación radical, que una revolución pertenece al pueblo y a una cierta visión de la historia. En realidad esto muestra que revolución es un concepto en disputa como cualquier otro y como cualquier otro puede ser un campo de conflicto y de luchas. El libro es interesante; pues muestra cómo las famosas transformaciones neoliberales llevadas a cabo por la dictadura de Pinochet, son en realidad grandes intervenciones políticas, con modificaciones, realizadas en breve plazo. Al mismo tiempo, el libro muestra cómo éstas son transformaciones estructurales, que repercuten económicamente en el país con niveles de crecimiento, y al mismo tiempo cómo reorganiza el espacio social. Evidentemente el libro no toca algunos aspectos menos apetecibles de dichas consecuencias, como son los grados de desigualdad, la baja cobertura de derechos sociales, la concentración de la riqueza, la externalización de los beneficios en conglomerados extranjeros, la consolidación de un modelo económico extractivo, entre otros etcéteras económicos. Pero es un elemento que ayuda a entender las representaciones de la estabilidad.

La extensión de la racionalidad de mercado a toda las estructuras sociales que hoy se experimenta en Europa, y que hemos experimentado salvajemente en Chile, requiere una percepción general de crisis, desastre, o como dice Foucault, una situación de adversidad. Lo único que puede justificar un cambio estructural de tales dimensiones, es una grave situación de adversidad. La crisis actual repre-

26 La expresión revolución silenciosa ha sido posteriormente usada también por Aznar en el contexto español, para ilustrar sus propias reformas económicas. 
senta para Europa esta oportunidad, esta situación de adversidad que se ha llevado a un extremo catastrófico y que permite reforzar la representación de una cierta derecha. En realidad se trata de la derecha de la revolución silenciosa, una derecha que quiere llevar a cabo una transformación radical de la sociedad actual, tanto o más radical que la de los proyectos fascistas; pero que se ha alejado de la representación de la derecha futurista. Las medidas anticrisis se representan como la forma de salvar Europa, cuando en realidad se trata de una conquista. Pero una conquista distinta a las pretendidas por el fascismo utópico que ponía en juego una gigantomaquia sobre el futuro y sobre las representaciones de la historia. En este caso, se trata de conquistar el presente a través de una estrategia pragmática que desactiva la idea de historia y con ella la posibilidad de los proyectos históricos. Se requiere, del mismo modo, un discurso crítico sobre los proyectos históricos, capaz de salir de las trampas políticas y epistémicas del siglo XX, y que ponga en jaque esta 'incapacidad de historia' de la derecha pragmática.

\section{Bibliografía}

AGAMBEN, Giorgio. El Reino y la Gloria. Por una genealogía teológica de la economía y el gobierno. Homo sacer II, 2. Pre-textos, Valencia, 2008.

Homo sacer I. El poder Soberano y la Nuda Vida, PreTextos, Valencia, 1998.

BORÓN, Atilio. Imperio e Imperialismo: Una lectura Crítica de Michael Hardt y Antonio Negri. CLACSO, Buenos Aires, 2002.

DERRIDA, Jacques. La bestia y el soberano; Volumen I, 2001-2002. Manantial, Buenos Aires, 2010.

ESPOSITO, Roberto. Bíos, Biopolítica y Filosofía, Amorrortu, Buenos Aires, 2006.

Comunidad, inmunidad y biopolítica. Herder, Barcelona, 2010. 
Confines de la Político. Nueve pensamientos sobre política. Trotta, Madrid, 1996.

FOUCAULT, Michel. La arqueología del Saber. Siglo XXI, Buenos Aires, 1999, pp. 345-346.

HARDT, Michael. NEGRI Antonio. Multitud. Guerra y democracia en la era del imperio. Debate, Barcelona, 2004.

NEGRI, Antonio. Imperio. Trad. Alcira Bixio. Paidós, Barcelona, 2002.

HOLLERICH, Michael. Catholic Anti-Liberalism in Weimar: Political Theology and its Critics. En KAPLAN, Leonard; KOSHAR, Rudy. «The Weimar Moment: liberalism, political theology and law». Lexington, Maryland, 2012.

NANCY, Jean Luc. La creación del Mundo o la mundialización, Paidós, Barcelona, 2003.

El sentido del Mundo, La Marca, Buenos Aires, 2002.

NEGRI. Antonio. Guías. Cinco lecciones en torno a Imperio. Paidós, Barcelona, 2004.

NICHTWEIß, Barbara. Analogías y oposiciones. Los Tratados teológicos de Erik Peterson en la perspectiva de la relación Iglesia-Estado. En «COMMUNIO». III Época, Año 25, Octubre-Diciembre, 2003.

Erik Peterson. Neue Sicht auf Leben und Werk. Herder, Freiburg, 1994.

VIRNO, Paolo. Gramática de la multitud. Para un análisis de las formas de vida contemporáneas. Traficantes de sueños, Madrid, 2003. 